\title{
A Retrospective Study of Fistula in Ano \& Primary Sphincter Repair (Sphincteroplasty) in Complex Fistulas
}

\author{
Chandu Sambasivudu ${ }^{1}$, Chandu Vineela ${ }^{2}$ \\ ${ }^{1}$ Department of General Surgery, NRI Medical College, Sri Venkateswara Nursing Home, Tenali, Andhra Pradesh, India. \\ ${ }^{2}$ Department of General Medicine, NRI Medical College, Sri Venkateswara Nursing Home, Tenali, Andhra Pradesh, \\ India.
}

ABSTRACT

\section{BACKGROUND}

Fistula in ano is a common perianal disease of the mankind. It is secondary to mainly cryptoglandular infections \& abscess. Persistence of chronic infection will lead to fistula formation. ${ }^{1}$ Management of high-level fistulas is complicated due to incontinence, which is troublesome; hence, many procedures have been tried by many surgeons, but without any supremacy over others. Immediate reconstruction of divided sphincter muscle will give good result. ${ }^{2}$ We have done fistulectomy \& repair of the external anal sphincter \& followed for the last two decades with no incontinence \& minimal recurrences.

\section{METHODS}

192 cases of fistula in ano for the last 20 years operated by a single surgeon $\left(1^{\text {st }}\right.$ author) were studied \& were followed up to now. The differences, in the selection of cases, surgical skill \& post-operative management are excluded in the study by including cases done by a single surgeon (first author) only. 136 males \& 56 females were operated. Intersphincteric $45.8 \%$, trans-sphincteric $49 \%$, high level fistulas $5.2 \%$, trans-sphincteric \& high fistulas with considerable external sphincter loss (54 cases) were repaired with 1-0 Vicryl. Fistula in ano is associated with haemorrhoids in 24/192 \& ano rectal abscess (20/192). Fistulotomy done in 16/192, simple \& subcutaneous tracts - fistulectomy done in $65 \%$. Curetting of the high tracts done in $16 / 192$.

\section{RESULTS}

Males are predominantly affected $70.8 \%$. This is more common in $3^{\text {rd }}$, $4^{\text {th }} \& 5^{\text {th }}$ decades (80.1\%). Single external opening was seen in (90\%). Posterior \& lateral fistula tracts are more commonly seen in (89.6\%). Non-specific pyogenic infective pathology is seen $99 \%$. Recurrences- 6/192. Time taken to heal is 3-6 weeks. Incontinence is not seen in any case. No recurrence or incontinence seen in primary sphincter repair of 54 cases.

\section{CONCLUSIONS}

Primary sphincter repair is simple \& best procedure with minimal or no recurrence \& decreases the healing time. It is more suitable \& advised in fistulas with considerable external sphincter loss.

\section{KEY WORDS}

Fistula in Ano, External Anal Sphincter, Abscess, Sphincter Repair, Fistulotomy, Fistulectomy, Anal Gland, Incontinence, Haemorrhoids \& Recurrence

\begin{abstract}
Corresponding Author: Dr. Chandu Sambasivudu, D. No. 22-7-21, SVN Home, Kothapeta, Tenali-522201, Guntur Dist., Andhra Pradesh, India. E-mail:dr.ch.sivudu@gmail.com
\end{abstract}

DOI: $10.14260 / \mathrm{jemds} / 2020 / 244$

Financial or Other Competing Interests: None.

How to Cite This Article: Sambasivudu C, Vineela C. A retrospective study of fistula in ANO \& primary sphincter repair (sphincteroplasty) in complex fistulas. J. Evolution Med. Dent. Sci. 2020;9 (14):1126-1130, DOI:
Submission 02-02-2020,

Peer Review 14-03-2020,

Acceptance 20-03-2020,

Published 06-04-2020. 


\section{BACKGROUND}

Fistula in Ano is a chronic abnormal communication from anorectal lumen to outside skin, and is usually lined by granulation tissue to some extent. External opening may lie anywhere from perineum, buttock, vagina. ${ }^{3}$ We observed external openings at scrotum \& thigh also. It is a common peri anal disease, with incidence varies from $9^{4}-20^{1}$ cases per 1 lakh population. It is more common in (males 12.3 per 1 lakh \& 5.6 in females ${ }^{1}$ ). 3 - 5 decades are more commonly effected. ${ }^{1}$ Fistula in ano is usually secondary to crypto glandular infection \& abscess formation. It is mainly due to nonspecific pyogenic infection. Specific infections like tuberculosis actinomycosis, Crohn's disease \& LGV \& HIV causes fistula in Ano. It is caused by injuries either outside or in the lumen of Ano rectum like fish bone. ${ }^{4}$ malignancy of anal canal \& rectum will produce fistulas. ${ }^{5}$ HIV \& secondary infections cause ano rectal abscess \& fistulas.

Management of fistula in ano is difficult in

1. High level fistulas crossing the external anal sphincter.

2. Multiple fistula tracts \& external openings.

3. Tracts going higher regions through either sub mucosally, intersphincteric or para rectally and in the ischiorectal fossa - Horseshoe fistulas (complex fistulas). Recurrence after fistulotomy varies from $0-26.5 \%{ }^{6}$ mainly due to incomplete removal of the infected material \& improper post-operative management. Complete healing of the fistula takes months. Two stage repair is required in some cases.

The complicating problem is incontinence following fistula surgery, mainly due to injury to the continent mechanism. Hence our aim of fistula management is to remove all infected material \& infectious process - there by decreasing the recurrence rate, preserve the continence mechanism and decrease the healing time. To achieve this, we are doing fistulectomy \& primary external sphincter repair keeping the wound open for trans-sphincteric fistulas \& complex fistulas with considerable sphincter involvement. We have analysed 192 cases of fistula surgery done by single surgeon for 2 decades \& enquired personally about their outcome regarding recurrence of any similar abscess or fistula \& the incontinence to flatus or faeces.

\section{METHODS}

It is a retrospective analytical study of 192 cases of fistula in ano of various categories. The differences in the selection of cases, surgical skill \& post-operative management are excluded in the study by including the cases operated by single surgeon in one hospital. We have done fistulectomy or fistulotomy by open surgery only. We have not used any advanced equipment or different modes of surgical management which are found to be not superior to open fistulectomy. We have done Primary external sphincter repair with 1-0 vicryl interrupted sutures, where fistula track traversing the sphincter muscle. Where the sphincter tract is more than $4 \mathrm{cms}$ in length. In inter sphincteric or trans sphincteric fistulas where track length is less than $3 \mathrm{cms}$, we have done only fistulectomy. All cases were done under low spinal anaesthesia. In some cases where fistula is associated with small peri anal abscess or multiple track abscess they are drained thoroughly \& fistulotomy was done. Where the fistulas track is going up towards pelvis either through inter sphincter plane or para rectal plane. We have curetted all granulation tissue without injuring the rectal mucosa or sphincter mechanism muscles. We have done haemorrhoidectomy along with fistulectomy - In cases where they are associated.

\section{Post-Operative Treatment}

1. Primary dressing after $24 \mathrm{hrs}$ unless abscess is there.

2. Daily dressings with hydrogen peroxide $\left(\mathrm{H}_{2} \mathrm{O}_{2}\right)+$ normal saline, + povidone iodine solution personally.

3. Sitz baths TDS or QID

4. Antibiotics and other supportive treatment.

\section{RESULTS}

Two separate fistulas with separate internal openings seen in female patients. Patients' age ranged from 20 to 78 years are seen in our series. Details are shown in table No: 1

\begin{tabular}{|c|c|c|c|c|}
\hline Age & Males & Female & Total & Percentage \\
\hline $20-30$ & $48(25 \%)$ & $16(8.3 \%)$ & 64 & $33.3 \%$ \\
\hline $31-40$ & $36(18.75 \%)$ & $20(10.42 \%)$ & 56 & $29.1 \%$ \\
\hline $41-50$ & $26(13.5 \%)$ & $8(4.2 \%)$ & 34 & $17.7 \%$ \\
\hline $51-60$ & $18(9.4 \%)$ & $12(6.3 \%)$ & 30 & $15.7 \%$ \\
\hline $61-80$ & $8(4.2 \%)$ & 0 & 8 & $4.2 \%$ \\
\hline Total & $\mathbf{1 3 6}$ & $\mathbf{5 6}$ & $\mathbf{1 9 2}$ & $\mathbf{1 0 0} \%$ \\
\hline \multicolumn{5}{|c|}{ Table 1. Age and Sex Wise Distribution } \\
\hline
\end{tabular}

We have $94.8 \%$ of intersphincteric \& trans sphincteric fistulas - as shown in table no: 2

\begin{tabular}{|c|c|c|c|c|}
\hline Sl. No. & Type of Fistula & Male & Female & \\
\hline 1 & Inter Sphincteric & 56 & 32 & $45.8 \%$ \\
\hline 2 & Trans Sphincteric & 70 & 24 & $49 \%$ \\
\hline 3 & Extra Sphincteric & \multirow[t]{2}{*}{10} & 0 & $5.2 \%$ \\
\hline \multirow[t]{2}{*}{4} & Supra Sphincteric & & & \\
\hline & Total & 136 & 56 & 192 \\
\hline
\end{tabular}

Single external opening 174/ 192 cases - 90\%.

Multiple external openings 18/ $192-9.4 \%$

Posterior \& lateral fistula tracts $-172 / 192-89.6 \%$

Anterior fistulas tracts 20/ $192-10.4 \%$ -

External openings are at scrotum.

Primary fistulas operated - 180/ $192-93.7 \%$

Recurrent fistulas operated - 12/ $192-6.3 \%$

\section{Pathology Wise Analysis}

Nonspecific pyogenic cases - 190/ 192 - 99\%. Tuberculosis 2/192-1.04\%. HIV associated fistulas are seen in 10 persons. They are not operated. Put on ART treatment, + antibiotics majority of them are healed. They are not included in the above study. Crohn's, ulcerative colitis \& traumatic \& malignant fistulas are not seen in our study. Fistulas associated with peri anal abscess are seen 20 cases. 20/192$10.4 \%$. Fistulas associated with internal haemorrhoids are seen in 24 cases $24 / 192-12.5 \%$. Females are proportionately more involved with haemorrhoids 12 / $56-21.4 \%$. Males 12 / $136-8.8 \%$. 


\section{Management Wise Analysis}

Aim of Treatment

1. Removal of entire infected tissues \& clearance of the all tracts of infected material there by decreasing the recurrence rate.

2. Preserving the patient's continence mechanism to both flatus and faces.

3. Decrease the wound healing time.

4. Decreasing the cost of treatment.

5. Using less equipment.

To achieve the above criteria, we need to excise the entire fistulous tract including the muscles coming in the way. Hence, we have done fistulectomy in majority of the cases \& repaired the divided external \& internal sphincter muscles with 1 - 0 Vicryl interrupted sutures, whenever the fistulous tract is more than $3-4 \mathrm{cms}$ in length. When the divided external sphincter muscle is significant, we always repaired it. When the fistula tract is small in length - we left it alone. Intersphincteric \& trans sphincteric cases of 176 were operated \& fistulectomy done. Out of 176, 122 are simple sub cutaneous inter sphincteric fistula \& low trans sphincteric fistulas with minimal external sphincter loss, where we have done only fistulectomy. The remaining 54 cases long fistulas tract involving the significant amount of external sphincter fistulectomy with primary sphincter repair was done 54/192 - 28.1\%. Majority of them are simple \& subcutaneous inter sphincteric fistulas hence simple fistulectomy was done $122 / 192-63.5 \%$.

\section{Fistulotomy}

It is done in 16 cases $-16 / 192-8.3 \%$. Where it is associated with abscess - fistulotomy done \& when the track is going high \& infected material is present - curetting done either in inter sphincter space or para rectal or secondary blind tracks in 16 cases $-16 / 192-8.3 \%$.

\section{No Recurrences in Sphincter Repair Patients}

Incontinence is not observed to either faeces or flatus in any patient. External wound persisted after 2 months in six people, who have associated with abscess \& tracts are going higher. We have curetted only but not excised sphincter muscles in those cases due to incontinence fear. Some people have gone to homeo \& other modalities. The remaining 186 healed well Success rate - 186/ 192 - 97\% Time taken to complete healing, $3-6$ weeks depending on depth of wound.

\section{DISCUSSION}

Fistula in ano is one of the most common ano rectal disease ${ }^{1}$ \& the surgical treatment is challenging to the surgeon because of high incidence of recurrences \& incontinence (24$50 \%), 8$ specially so in complex fistulas, hence many modalities of management options are available (Gottgens KW). ${ }^{9}$ The best surgical treatment for high crypto glandular peri anal fistulas could not be made out. Riyadh Mohamad Hasan from Iraq reported the fistulas are more common in male $92.64 \%$ \& female $7.35 \%$ Patients age range from $20-68$ years. He noted close relationship between ano rectal abscess \& fistulas. Fistula formation after abscess drainage is $45.58 \%$ in his series \& most common site of internal opening is posterior \& left lateral position.

In our series also males are $70.8 \%$ effected \& females $29.2 \% .3^{\text {rd }} 4^{\text {th }} \& 5^{\text {th }}$ decades are more commonly affected more than $82 \%$. Posterior \& lateral fistulas tracts are $89.6 \%$. Both series corroborating in case of age of involvement \& position of fistula tract. But the percentage of male patients are $70.8 \%$ in our series whereas $92.64 \%$ in his series. Ramanujam PS et al, Prasad ML et al stressed the careful examination under anaesthesia \& operate accordingly. They observed recurrence rate $1.8-3.7 \% .{ }^{10}$ We also relied more on clinical examination \& under anaesthesia. The recurrence rate is $3.1 \%$ which is nearly the same in our series. Malgorzata Kolodziejczak, et al reported recurrence rate of anal fistula surgery from $0-26.5 \%{ }^{6}$. Most recurrences are in high supra sphincteric \& extra sphincteric fistulas, Chron's disease, low immunity or decreased immunity \& diabetic mellitus patients. They advocated 1 . good pre-operative diagnosis. 2. Appropriately correct surgical procedure. 3. Correct post-operative management to decrease the recurrence rate. We have not seen Chron's fistulas in our series. Chron's disease is uncommon in our part of rural India. We concur with the the above principles of fistula in ano surgery to decrease the recurrences.

Hamadani A etal USA reported two-fold increased risk of recurrence in patients $<40$ years \& non-diabetics. Sex, Smokers, HIV status \& peri operative anti biotics have no differences in recurrence. ${ }^{11}$ We have seen 10 cases of HIV associated peri anal abscess \& fistulas, they have responded well to medical treatment (not operated - Not included in study) Garcia - Aguilar J quoted factors responsible ${ }^{12}$ for post-operative incontinence \& recurrence are- 1. Complex type. 2. Horseshoe extension. 3. Lack of identification internal opening. 4. Lateral location of the internal fistulous opening. 5. Previous fistula surgery. 6. Surgeons performance. 7. Female Sex. ${ }^{12}$ We agree with the same findings hence surgeries done by single surgeon (1 ${ }^{\text {st }}$ Author) are included in our series. Qyah HM et al in "Meta-analysis of randomized clinical trials comparing drainage alone vs primary sphincter cutting procedures for anorectal abscess fistula". Reported after studying of 405 patients - sphincter cutting procedures for ano rectal fistulas resulted in $83 \%$ reduction in recurrence rate. However, there was tendency to higher incontinence to flatus/faeces and soiling. ${ }^{13}$ This shows unless we remove entire infected material including the sphincter muscle recurrence rate will not come down. Once sphincter is divided - incontinence rate goes higher. Westerterp $M$ etal reported incontinence rate of $24-50 \%{ }^{8}$ after fistulotomy hence the primary sphincter repair is a necessity.

Jacob $\mathrm{TZ}$ et al in a study of randomized controls trials comparing operative procedures for ano rectal fistula shows no significant difference in recurrence/ incontinence rates in different procedures like fibrin glue injections or plug application. Mucosal advancement flap procedures are better in continence wise. ${ }^{14}$ But it is complicated procedure than sphincter repair. S. Alasari et al reported Ligation of inter sphincteric fistulas tract (LIFT) Procedure originally designed by Rojanasakul et al) to decrease the incontinence met with initial success \& excitement. Post-operative complications $1.88 \%$, healing rate is $81.3 \%$, recurrence rate $7.58 \%$, healing period is $8-15$ weeks. ${ }^{15}$ According to Sirany AM et al primary healing rate ranges from $47 \%-95 \%$ in the LIFT procedure. ${ }^{16}$ 
Yansong et al reported only $60 \%$ healed completely \& $40 \%$ recurrences \& 6 complications in LIFT procedure. It is better for patients who had one to two operations earlier. ${ }^{17}$ Higher rate of recurrences is not acceptable, even though it is latest with minimal incontinence. It takes long time for the healing of wounds.

\section{Video-Assisted Anal Fistula Treatment (VAAFT)}

P. Meinero and Mori et al reported - Even though it is a novel procedure - minimal access modality, we are able to see the internal opening endoscopically in this. Fails to remove all infected material. Primary healing achieved in $73 \%$ within 2 3 months. It goes to $87 \%$ after one year ${ }^{18}$. Long term results are awaited hence we cannot take it as a gold standard. The American society of Colon Rectal surgeons in "practice Parameters for the Management of Perianal Abscess and Fistula-in-Ano", Scott R. Steele, MD. Ravin Kumar etal, strongly advocated fistulotomy \& fistulectomy. Strong recommendations based on moderate evidence than other modalities like fistula plug, Fibrin glue, lift etc. ${ }^{19}$

Fistulotomy \& fistulectomy are gold standard procedures practised by the surgeons for decades. But in complex trans sphincteric \& high fistulas two stage procedure using with or without seton application is advised \& followed. It is cumbersome procedure takes long time \& needs two surgeries with loss of many working days \& cost. Incontinence rate is also more. To avoid two stage procedure \& decrease the incontinence rate, we started fistulectomy with repair of the divided sphincter muscle. External anal sphincter muscle is a striated muscle \& heals well just like in other straited muscle. Skin \& sub cutaneous tissues are left open to allow infected discharges drained out \& heal by secondary intention, but decreases the depth of wound there by healing time is decreased. We assessed sphincter tone per rectally \& daily dressing done personally along with other management. We got good results for last two decades. The same is corroborated from other authors also - Mospcgni D1, Pironi D2 et al, 2017.

\section{CONCLUSIONS}

Males are more commonly affected $70.8 \% .3^{\text {rd }}-5^{\text {th }}$ decade people are more commonly affected $(82 \%)$. Inter sphincteric $\&$ trans sphincteric fistulas are more common (94.8\%). Most of fistulae in ano are secondary to crypto glandular infection $\&$ abscess $(99 \%)$ in our series. Posterior \& lateral tracts are more common $(89.6 \%)$. Fistulectomy \& primary sphincter repair is the best modality of treatment out of all the available procedures with low recurrence $\&$ nil incontinence rates. It is less expensive. No special equipment is required. It is the future hope of the fistula surgery. ${ }^{20}$

\section{REFERENCES}

[1] Hasan RM. Incidence of fistula after management of perianal abscess. Journal of Coloproctology (RIO J) 2016;36 (4):216-9.
[2] Williams N, O'Connel PR. Text book of Bailey and Love's - Short practice of surgery. 25 th edn. CRC Press 2008: p. 1264.

[3] Williams N, O'Connel PR. Text book of Bailey and Love's - Short practice of surgery. $25^{\text {th }}$ edn. CRC Press 2008: p. 1262.

[4] Sainio P. Fistula-in-ano is a defined population. Incidence and epidemiological aspects. Ann Chir Gynaecol 1984;73 (4):219-24.

[5] Sabiston DC Jr. Davis-Chriotopher Textbook of surgery. The biological basis of modern surgical practice. $10^{\text {th }}$ edn. WB Saunders Company 1977: p. 1145.

[6] Kolodziejczak M, Sudol-Szopinska I. Causes of recurrences of anal fistulae. Borgis - New Medicine 2005;8 (4):54-6.

[7] Parks AG, Gordon PH, Hardcastle JD. A classification of fistula in ano. British Journal of Surgery 1976;63 (1):112.

[8] Westerterp M, Volkers NA, Poolman RW, et al. Anal fistulotomy between Skylla and Charybdis. Colorectal Dis 2003;5 (6):549-51.

[9] Gottgens KWA, Smeets RR, Stassen LPS, et al. Systematic review and meta - analysis of surgical interventions for high cryptoglandular perianal fistula. Int J Colorectal Dis 2015;30 (5):583-93.

[10] Ramanujam PS, Prasad ML, Abcarian H, et al. Perianal abscesses and fistulas. A study of 1023 patients. Dis Colon Rectum 1984;27 (9):593-7.

[11] Hamadani A, Haigh PI, Liu IL, et al, Who is at risk of developing chronic anal fistula or recurrent anal sepsis after initial perianal abscess? Dis Colon Rectum 2009;52 (2):217-21.

[12] Garcia-Aguilar J, Belmonte C, Wong WD, et al. Anal fistula surgey. Factors associated with recurrence and incontinence. Dis Colon Rectum 1996;39 (7):723-9.

[13] Quah HM, Tang CL, Eu KW, et al. Meta-analysis of randomized clinical trials comparing drainage alone vs primary sphincter - cutting procedures for anorectal abscess - fistula. Int J Colorectal Dis 2006;21 (6):602-9.

[14] Jacob TJ, Perakath B, Keighley MRB. Surgical intervention for anorectal fistula. Cochrane Database Syst Rev 2010;12; (5):CD006319.

[15] Alasari S, Kim NK. Overview of anal fistula and systematic review of Ligation of the Intersphincteric Fistula Tract (LIFT). Techniques in Coloproctology 2014;18 (1):13-22.

[16] Sirany AM, Nygaard RM, Morken JJ, The Ligation of the intersphincteric fistula tract procedure for anal fistula: a mixed bag of results. Dis Colon Rectum 2015;58 (6):60412.

[17] Xu Y, Tang W. Liagation of intersphincteric fistula tract is suitable for recurrent anal fistulas from follow-up of 16 months. Article ID 3152424, Biomed Research International 2017;2017:4.

[18] Meinero P, Mori L. Video-assisted anal fistula treatment (VAAFT): a novel sphincter-saving procedure for treating complex anal fistulas. Tech Coloproctol 2012;16 (1):111. 
[19] Steele SR, Kumar R, Feingold DL, et al. Practice parameters for the management of perianal abscess and fistula-in-ano. Disease Colon \& Rectum. 2011;54 (12):1465-74.
[20] Ratto C, Litta F, Parello et al. Fistulotomy with end-toend primary sphincteroplasty for anal fistulas results from a prospective study. Disease of Colon Rectum 2013;56

(2):226-33 